\title{
Key Performance Indicators Of Public Universities Based On Quality Assessment Criteria In Thailand
}

Kritsana Sukboonyasatit, Khonkean University, Thailand Chaiwit Thanapaisarn, Khonkean University, Thailand Lampang Manmar, Khonkean University, Thailand

\begin{abstract}
The research objective was to develop public universities' key performance indicators. Qualitative research and interviews were employed with each public university's senior executive and quality assessors. The sample group was selected by the office of the public sector development commission and Thailand's public universities can be separated into three groups based on their quality assessment score: 1) the high scoring group, 2) the moderate scoring group, and 3) the low scoring group. The results showed that the high scoring group had set a clear strategic context such as vision, mission, core values and corporate goals. In the case of the moderate scoring group it was found that some sections of the strategic context, such as the vision and mission, had already been defined, but corporate goals were yet to be determined. The strategic context was not clear and remained inactive for the low scoring group. In additional, each public university should establish two different sets of key performance indicators; first, a common key performance indicator which is aligned with the public university mission to enhance macro education, and which can be separated by five assessment perspectives as follows: 1) to produce graduates, 2) to promote and expand the university's research, 3) to provide academic services, 4) to preserve and promote the arts, culture and heritage, and 5) to manage the university. The second specific key performance indicator should be aligned with the university's strategic context, especially its vision and goals.
\end{abstract}

Keywords: Key Performance Indicators; Public University; Assessment; Management Quality

\section{INTRODUCTION}

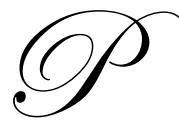

ublic universities in Thailand are now intimidated by both the globalization and boundless transfer of information, and the aggressive progress of technology. Trade and services liberalization according to the General Agreement on Trade in Services (GATS) as well as the Free Trade Area (FTA) have impacted university sector businesses, as found in universities from other countries and international universities which intend to formulate learning management in Thailand, focusing on maximizing profits (Charat Suwanwela, 2002; Suthum Aareekul and team, 1997). This situation results in competition for recruiting potential students. In addition, government reform policies geared to increase the efficiency of public management (Office of the Public Sector Development Commission, 2003) have resulted in government organizations, including public universities, reorganizing various aspects of their administration. Public management patterns in the past that concentrated on supervisors have shifted to focus on the people who receive services. Listening to others' opinions, management participation, transparency, ease of assessment, speed, quality, and efficiency in operation were all emphasized. Budgets have also become an influence in public management. As a result, public universities are now facing pressure to transform their administrative management in order to maintain a competitive advantage. Strategic management approaches were employed including determining a vision, mission, objective, strategic plan for implementation, key performance indicators, and a performance evaluation system. 
The government was given a key supervisory role in the achievement of public university performance expectations to develop public universities to meet international management standards. Related organizations have been assigned to supervise the public universities; including the Office of the Public Sector Development Commission because the public universities were a public organization. The Office of the Higher Education Commission as the original affiliate also has a role to assess administrative management effectiveness through the key performance indicators set by each organization. Hence, the public universities have to operate based on their self-determined key performance indicators to meet objectives and complete their strategic plan for organizational development, together with the key performance indicators from other organizations that are responsible for supervising the public universities with their own assessment criteria and key performance indicators; such as 48 key performance indicators from the Office of the Public Sector Development Commission, 43 key performance indicators from the Office of the Higher Education Commission, and 43 key performance indicators from the Office for National Education Standards and Quality Assessment. Under these circumstances, each year public universities have to collect information to prepare a self assessment report for the three organizations, with a total of 134 key performance indicators, which consists of an average of 45 key performance indicators from the internal quality assessment and 177 key performance indicators from both internal and external assessment. This involves preparation for assessments which take place more than 10 times per year from both internal and external units.

In order to assess quality management to increase a university's standing and meet international standards, the government determined that public universities have to improve their administrative management organization according to the Thailand International Public Sector Standard Management System and outcomes. Its assessment was later improved using results based management. Management concepts founded on a balanced scorecard were also employed as guidelines for creating a performance agreement which contains an assessment of 4 dimensions, including effective performance based on mission, quality in services, public performance efficiency, and organizational improvement. In present its concept has evolved following the entrance of the public sector management quality award or PMQA, which is derived from the criteria and concepts of the Malcolm Baldrige National Quality Award or MBNQA (Office of the Public Sector Development Commission, 2003). For quality assessment of other countries, there are discussions in the research of key performance indicator developments regarding quality of education in a model system consisting of input, process, and output (Oaks, 1986, Bomgart, 1994) including quality of teachers, facilities for educational administration, quality and sufficient equipment and materials for students, and university quality management and control.

According to the study on current situations of assessment and key performance indicator systems of universities, there were many problems revealed, including 1) wide range of auditors in terms of number and details of assessment criteria like the Office of the Higher Education Commission, the Office for National Education Standards and Quality Assessment, and the Office of the Public Sector Development Commission. Each organization has a different approach and methods of quality assessment in terms of assessment criteria, quality indicators, and assessment time frame, such as calendar year, academic year, and fiscal year. 2) There are many key performance indicators, in total 132 indicators from all three assessment organizations, which results in a substantial undertaking for universities to prepare information for management quality assessment. 3) Assessment approaches are mainly results based, without placing much emphasis on the process that leads to the results. Even though the process is focused, systematic operational approaches that would lead to achievement and sustainable development are not considered. 4) Key performance indicators are currently determined based on new management theories, which have been employed internationally. However, they cannot reflect key success factors or quality management in the different context of each university, in terms of vision, mission, objective, strategic plan, group of students, size, number of subjects, and development levels of each university, all of which can be vastly different.

Under the current situation the main problem is that key performance indicators are unable to reflect performance according to the context of each university strategy, plus handle the weighty responsibility of preparing a significant amount of data for key performance indicators. These must be provided to auditors from three organizations and contain different principles and time frames, including results in implementation complications, time consumption, and numerous resources. Hence, the researcher realizes and is interested in examining guidelines for determining university key performance indicators that contain major characteristics including 1) university key performance indicators that are able to reflect the real level of quality management in the organization, which will lead to a competency to achieve the vision, mission, and strategic objectives; as well as to improve and develop the 
organization to be a sustainable high performance organization; 2) key performance indicators that are able to support all types of assessment systems and cover the main issues completely in order to reduce responsibility for data preparation; and 3) key performance indicators that are flexible enough to adjust to different contexts in different universities.

To begin with, research on key performance indicator improvement of quality management needs to examine the current situation. It is important to analyze what prevalent dimensions and which common key performance indicators are employed for assessing public universities. Are there similarities or differences in each set of assessment criteria from each organization? Key performance indicator collection, analysis, and synthesis are conducted in order to obtain the basic facts, which can be employed to gather opinions of university management to ensure current use of criteria, assessment dimensions, and key performance indicators. This leads to an improvement of assessment dimensions and key performance indicators that reflects the real quality management of public universities. It can also raise operational effectiveness according to its missions, plus can respond to public policies for maximizing the benefits of country development.

\section{RESEARCH OBJECTIVES}

1. To gather key performance indicators from the current assessment system

2. To comparatively analyze common key performance indicators of the current assessment system in order to obtain common key performance indicators among universities conforming to university contexts

\section{RESEARCH METHODOLOGY}

The research was conducted through document analysis, containing 1) guidelines for the external quality assessment of the Office for National Education Standards and Quality Assessment, 2) the manual for internal quality assurance of the Office of the Higher Education Commission, and 3) self assessment reports of universities and institutes focusing on producing graduate students and research under the Office of the Higher Education Commission, in total 19 organizations. A comparative analysis of key performance indicators of all assessment systems was undertaken. An analysis followed to classify dimensions based on the mission of each university, which consisted of 1) number of graduates, 2) research, 3) academic service, 4) art and culture preservation and management; in order to determine the appropriate indicators of each dimension that fit in with the individual character and context of each public university, and to ensure efficiency and effectiveness of management quality to meet organizational objectives. The sample group was determined based on the purposive sampling method (Chai Podhisita, 1997), which was unstructured selection. Process and method were not complicated but aimed to obtain a proper sample group for the concept, target, and objective of the research, which adhered to assessment management scores of the Office for National Education Standards and Quality Assessment and the Office of the Public Sector Development Commission as the criteria to select the sample group. In 2008, there were 2 institutes which obtained high quality assessment scores (higher than 4.25), 4 institutes received a medium score (3.50-4.25), and 2 were given a low score (lower than 3.50 ), out of 8 total institutes.

\section{The results revealed that:}

\section{The study of main characters and strategic contexts of public universities:}

Institute Group 1, including public universities, obtained a high assessment score from the Office of the Public Sector Development Commission (higher than 4.25), and in this group scores have increased continuously. There are major common characteristics including status of having been established for a long time with a similar number of faculties, students, and personnel. Clear strategic contexts for implementation among the organization and all stakeholders are determined. With a personnel knowledge collection and information about the organization itself, knowledge is able to be transferred for teaching and learning processes, along with research and academic services, more effectively than at other institutes. The vision of this group emphasizes 3 main aspects, including 1) success of graduates, research, and academic works that meet international standards; 2) good governance management; and 3) efficient and sustainable management of physical and intellectual property. However, there are differences which consist of G-1.1 focusing on encouraging equality of educational opportunities, health promotion, relationships 
among personnel, and continuous personnel development. On the other hand, G-1.2 emphasizes creating channels for internal knowledge transfer among personnel, along with external learning; plus giving opportunities or creating channels for the community to participate in management, development, and performance implementation in order to solve and improve social problems as well as to conserve the arts, culture, and local wisdom. Regarding the organizational target aspect, this group determines clear targets with a process to share targets from the organizational level to the personnel level. The group also formulates evaluation and monitoring mechanisms to ensure target achievement, partnered with support for operational plan improvement to reach organizational targets.

Institute Group 2, including public universities, received a medium assessment score from the Office of the Public Sector Development Commission (score 3.50-4.25). The universities obtained a high score for this group, which contained similar characteristics to institute group 1, including the number of faculties, personnel, and students, plus the ratio of students to personnel. However, universities obtained a low score for this group by displaying a high ratio of students per instructor, which was reflected in the staff work load. It also shows an inverse relationship with the quality management assessment score. There are 3 common visions from this group consisting of 1) producing knowledgeable and competent graduates who meet international standards, with qualifications including intention, discipline, ethics, morals, public-based mindset, and identity; plus being adept at work, comfortable with all types of people, good at thinking, healthy, and good at problem solving; 2) producing quality research which meets international standards, focusing on knowledge and innovation in order to employ in teaching and learning improvement and community development, 3) up-to-date management system with flexibility, transparency, ease of assessment, good governance, and efficiency. Regarding organizational targets, only some universities determine organizational targets, with unclear processes or mechanisms to distribute targets at the organizational level to others, plus uncertainty in monitoring and improvement.

Institute Group 3, including public universities, obtained a low assessment score from the Office of the Public Sector Development Commission (lower than 3.50). The main failing characteristics consist of recent establishment, due to the fact that in the past they operated on a campus level or were an association of many institutes; which results in a varied organizational culture and management complications. Therefore, assessment scores have continuously decreased. The vision of this group contains 3 main aspects including 1) focusing on areas nearby the Mae Khong River due to the fact that there are two institutes located in north-eastern Thailand, in Laos and Cambodia; 2) producing graduates who have knowledge and ability along with morals and ethics; and 3) aiming to be a research center to develop and transfer knowledge. For the organizational target aspect, the institutes of this group do not determine clear targets. Strategies and operational plans are set but there are no processes or mechanisms for communication, transferring, or disseminating targets. Similar to the institute group 2, performance monitoring and improvement are not employed.

\section{The study of directions, trends, and threatened status:}

Directions, trends, and threatened status are all external factors affecting management quality of public universities. The findings reveal the opinions of the institute group 1 on directions, trends, and threatened status involving international factors, globalization, free competition, and market needs. On the other hand, institute group 2 gives precedence to resource limitations, knowledge transfer, the increasing number of universities, expectations from society, quality improvement on teaching and learning of morals and foreign languages, and quality of graduates. Further, institute group 3 focuses on public policies regarding independent status, creating skills, and the high quality of educational administration. In addition, the study displays that the government system and public reform provide yet another problem and obstacle for all three institute groups including focusing on organizational development to reach the international level for group 1, emphasis on quality improvement of the internal organization for group 2, and a limitation of organizational management for group 3.

\section{The study of public university achievement factors includes:}

- A clear, focused, and aligned management strategy for both the short-term and the long-term is implemented. The management strategy conforms to the university master plan, vision, mission, strategic plan, and other related plans. In addition, management has vision and leadership. 
- Quality of teaching and learning administration processes consist of a quality curriculum, processes, curriculum improvement, teaching and learning processes, extra activities support, qualifications, experiences, ethics, intention, responsibility, students' readiness, sufficiency and readiness of sites, plus equipment and materials for teaching and learning, networking, and educational quality insurance.

- Quality of research processes contain clear direction, policies focused on research, a personnel development process to create qualified researchers, a motivated compensation system, raising researchers' morale, the amount of work allocation supports doing research, build the institute's reputation, support networking with external organizations, research funding, support system for research funding, a database system, and knowledge management in the organization.

- Quality of academic service processes include reputation, accumulated experiences, academic publications, knowledge, ability, experience, personnel intention, motivated compensation system, quality of research database, supporting system, integration among academic services, research, plus teaching and learning, and an ability to access and respond to the community.

- Clear direction and policies of institute, emphasizing responsibility toward society and community with cooperation from personnel, sufficient funding to support activities for the society and community, integration of teaching and learning, research, academic services, and social responsibility.

- Management leading to sustainable organization combined with intention and leadership, efficiency and effectiveness of personnel and organizational development, clear objectives and strategic plan for implementation, personnel relationships, budget management, building reputation for institutes and networking development, good governance of university council and management, and management participation.

\section{The study of current management quality assessment system:}

The study of current management quality assessment system aims to examine dimension on management quality assessment and management quality indicators. It is found that:

- $\quad$ In the public performance assessment manual according to the university performance agreement in 1997, which the Office for National Education Standards and Quality Assessment employs as criteria to assess universities, there are 7 assessment standards, including (1) graduate student quality, (2) research and creative works, (3) academic services, (4) arts and cultural conservation, (5) institute and personnel development, (6) teaching and learning curriculum, and (7) quality assurance system; with a total of 48 indicators.

- In the educational quality assurance manual for universities in 1997, which the Office of the Higher Education Commission employs for assessment, there are 9 assessment factors: (1) philosophy, commitment, objective, and implementation plan, (2) teaching and learning, (3) activities to improve students, (4) research, (5) academic service for society, (6) arts and cultural conservation, (7) administrative management, (8) finance and budgeting, and (9) quality assurance system and mechanisms; with a total of 43 indicators.

- In the indicator and goal assessment manual based on university performance in 1997, which the Office of the Public Sector Development Commission employs for assessing public universities, there are 4 assessment dimensions, including (1) effectiveness, (2) service quality, (3) public works efficiency, and (4) organizational development; with a total of 43 indicators.

\section{Key Performance Indicators of current assessment system:}

Of the different indicators found in the assessment system, output indicators are the most commonly used, for a total of 65 indicators out of 134, or $48 \%$; whereas, input indicators are the next most commonly used, at 40 indicators or 30\%; and there were 29 process indicators or $22 \%$ of the total. Among all 3 organizations, the Office of the Public Sector Development Commission gives precedence to output indicators. 27 output indicators are employed out of 65, which is $42 \%$; while the Office for National Education Standards and Quality Assessment employs 24 output indicators, or 37\%; and the Office of the Higher Education Commission applies 14 output indicators, or $22 \%$. Reasons to support this varied indicator implementation among the 3 organizations are that the 
Office of the Public Sector Development Commission is responsible for assessing the results to achieve the public mission. Similarly, the Office for National Education Standards and Quality Assessment places an emphasis on building the confidence of learners and others who obtain services, which leads to a results-based focus. Major indicators regarding graduate results are separated into short-term and long term-results. The numbers of graduates who are able to get a job within 1 year, as well as satisfaction of employees, are considered short-term results; whereas long-term results include numbers of graduates and alumni who gain prestige in various areas, reflecting the quality of teaching and learning processes. In terms of the research dimension, it considers research that is accepted at the international level, able to be implemented practically, employed as a citation, and registered for a copyright. Regarding the academic service dimension, which considers academic services that are able to respond to needs and to increase the strengthening of the community and country, plus be accepted by other countries as academic service sources are included. The arts and cultural dimension includes effectiveness of conservation activities and developments in cultural identity strengthening. Lastly, for the administrative management dimension, achievements in meeting public policy are considered, along with short-term and long-term plans of the ministry, the Office of the Higher Education Commission, and universities; personnel development should focus on being ready for important missions; and strengthening the learning process and knowledge to meet international standards.

According to key performance indicator analysis on process, it is revealed that the Office of the Higher Education Commission determines the highest number of process indicators, which is 18 indicators out of 29, or 62\%; whereas the Office for National Education Standards and Quality Assessment and the Office of the Public Sector Development Commission employ only 5 and 6, respectively. It is because the Office of the Higher Education Commission has a lead role to supervise public universities to meet standards, under the concept that if universities have high-quality, complete, systematic processes, positive results will follow. However, graduate production of all three organizations employs the same indicator regarding the process dimension, with a learnercentered focus. This is totally different from the past, where learners' opinions were ignored in process improvement to ensure learning effectiveness and the emphasis was on the standard of curriculum and instructors. For key performance indicators on research, assessment places priority on the system and mechanisms to support research production and knowledge management because those have a direct impact on research effectiveness. Regarding the academic services, arts and cultural conservation dimension; the academic system and mechanisms for society, the community, and the nation are all considered. However, the Office of the Higher Education Commission places great precedence on organizational management. Ten key performance indicators are employed, including good governance for management, management leadership, achievement level of institute development participation by outsiders, risk management implementation, dissemination of indicators and objectives from organizational level to personnel level, expenditure analysis, and finance and budget assessment.

Regarding key performance indicator analysis on input, the Office for National Education Standards and Quality Assessment determines the highest number of indicators in this dimension, 19 indicators out of 40, or 48\%; whereas, the Office of the Higher Education Commission and the Office of the Public Sector Development Commission employ 11 and 10 indicators, respectively; because the Office for National Education Standards and Quality Assessment is responsible for assessing educational management to ensure quality of educational institutes, focusing on goals, principles, and approaches of educational management at different levels according to the national education laws, which results in a greater consideration of input indicators. For the graduate production dimension, assessment considers factors affecting graduate quality consisting of educational qualifications, academic positions, sufficient number of instructors, and equipment and materials to support teaching and learning. For the research dimension, assessment aims for internal and external support for funding and the percentage of teachers who receive internal and external research scholarships. According to the academic service dimension, assessment includes the average number of teachers providing academic and professional services and responding to needs; improving and increasing the strengthening of society, community, nation, and other countries. However, there is no key performance indicator determined for the arts and cultural conservation factor. In terms of management, assessment emphasizes the potential of the management database system; teaching, learning, and research; management leadership; institute development participation by outsiders; risk management implementation; dissemination of indicators and objectives from the organizational level to the personnel level; expenditure analysis, and finance and budget assessment; and to ensure that institutes employ appropriate, complete, and sufficient factors for process implementation leading to the results. 


\section{Improvement of university management quality indicators:}

The research findings conducted through questionnaires asking opinions of the sample group including university management members, management quality assessors, and personnel representatives, revealed that assessment dimensions and key performance indicators reflecting management quality include:

- Assessment of the graduate production dimension consists of assessment of output, process, and important factors involved with graduate production to ensure desirable qualifications, to be knowledgeable, and to have morals, ethics, and the ability to adapt themselves and their learning competency. Three indicators are employed for assessment, including 1) percentage of undergraduates who are employed within 1 year, 2) satisfaction of employees; and 3) graduates or alumni who obtain prestige in academic, professional, moral, ethical and other related areas.

- Assessment of the research dimension contains quality of research and creative works that meet research objectives, and are reliable and practical. Three indicators are employed including 1) research and creative works that are published, publicized, or implemented in both the domestic and national levels, 2) satisfaction of research funding providers, and 3) satisfaction of researchers.

- Assessment of the academic service dimension is involved with the quality of academic service implementation that accesses and responds to the needs of people who receive services and to the community. Three indicators are considered for assessment including, 1) activities/projects of academic services and professions that respond to the need to develop and increase the strengthening of society, community, nation, and other countries; 2) the satisfaction level of people who obtain academic services; and 3) the number of academic service sources that are accepted at the national and international level.

- Assessment of the arts and cultural conservation dimension considers the system, mechanism, approach, and effectiveness of knowledge improvement for arts and cultural conservation. Two indicators are employed including 1) effectiveness of arts and cultural conservation, and 2) participation of leaders and personnel in arts and cultural conservation.

- Assessment of the organizational development and management dimension employs institute management system development to increase competitive competency through the mechanism of teaching and learning process improvement and organizational development, plus management efficiency and readiness preparation of the fundamental structure for learning, presentation, and research. Four indicators are implemented including 1) achievement of a personnel resource management system and mechanisms to develop and maintain personnel to ensure their quality and efficiency; 2) administrative management through the achievement level of public management quality improvement; 3) public performance efficiency through cost per unit; and 4) quality assurance through achievement of internal quality assurance to ensure continuous educational quality improvement.

\section{RESEARCH DISCUSSIONS}

The study of organizational profile and strategic context, focusing on vision and goals, displays that institute group 1 that obtained a high score, determines a clear vision and goals. They also pay attention to communication and knowledge transfer to ensure personnel understanding conforming to the total quality management theory based on the Malcolm Baldrige National Quality Awards (MBNQA), which identified that an organization should determine a clear and practical direction, with communication to ensure personnel understanding that will lead to the achievement of vision and goals (The Office of the Thailand Quality Award, 2005), plus conforming to the balanced scorecard theory, which states that an important factor of organizational strategic implementation is to ensure that everyone in the organization has the same focus issue (Kaplan and Norton, 1992). In addition, the findings show that factors directly affecting the level of management score include mechanisms and processes of knowledge creation and collection at the organizational level; sufficient resources, especially human resources, both in quantity and competency; clear determination, transfer, and monitoring of vision and goals; and coverage of communication to encourage understanding and participation of all stakeholders.

The study on the current management quality assessment system of public universities reveals a comparison of the assessment system of the Office for National Education Standards and Quality Assessment consisting of 7 aspects including (1) quality of graduates, (2) research and creative work, (3) academic services, (4) 
arts and cultural conservation, (5) institute and personnel development, (6) curriculum, learning and teaching, (7) quality assurance system; and the assessment system of the Office of the Higher Education Commission containing 9 aspects, including (1) teaching philosophy, commitment, objective, and operational plan, (2) teaching and learning, (3) activities for student development, (4) research, (5) academic services for society, (6), arts and cultural conservation, (7) administrative management, (8) finance and budgeting, and (9) system and mechanism of quality assurance. Both systems conform to the total quality management theory based on the Malcolm Baldrige National Quality Awards (MBNQA) guidelines including 6 dimensions, which are 1) products and services, 2) studentcentered focus, 3) finance and marketing, 4) personnel, 5) effectiveness of teaching and learning processes, and 6) organizational leadership, good governance, and social responsibility. Most dimensions conformed to the standards, except student-centered focus, organizational leadership, and good governance. However, the Office of the Public Sector Development Commission employs assessment criteria with 4 dimensions, including dimension 1: mission achievement, dimension 2: service quality, dimension 3: efficiency of government service, and dimension 4: organizational development, which conform to the modern management theory and the balanced scorecard (Kaplan and Norton, 1992).

The research findings reveal that the three assessment organizations lack operational integration. This is evident from the duplication of key performance indicators and similar definitions, and a difference in assessment time frame seen in reports based on academic year, calendar year, and fiscal year. This results in excessive resource consumption for data collection prepared by universities. In addition, according to interviews with management, it is found that assessment organizations do not give precedence to communication and explanation of details, clear definitions, benefits from data collection for management purposes, or assessment results that lead to increases in organizational management improvement. Therefore, universities only report implementation results to the assessment organizations, without taking results into consideration to make decisions, plan, or improve organizations. University management bodies mostly perceive that reporting management quality indicators to public organizations is their responsibility, without seeing that it has management benefits and can lead to institute improvement. The researcher agrees that all assessment organizations should consider integration, plus agree on details of assessment dimensions, key performance indicators, and assessment time frame; in order to reduce duplication and responsibility to prepare public university results reports.

The results of key performance indicators of current public university management quality assessment systems display that there are 134 key performance indicators from the three assessment organizations, which results in a lengthy time to prepare information for reporting. It is also found that some indicators are duplicated, with only 87 different indicators. According to opinion surveys with management members and representatives from universities regarding appropriate key performance indicators for university management quality assessment that cover important university missions, there is agreement that only 15 indicators are suitable, including 3 indicators from the graduate production dimension, 3 indicators from the research dimension, 3 indicators from the academic dimension, 2 indicators from the arts and cultural conservation dimension, and 4 indicators from organizational management. From the findings, it is obvious that drawn from the responsibility to prepare information for assessment reports consisting of 134 indicators, only 36 indicators, or $11 \%$, are practically employed to reflect management performance and are applicable to universities' achievement of vision and goals.

\section{Suggestions}

According to the study results of institutes which received a high score for management quality assessment, it is found that those institutes place emphasis on clear vision and goal determination, as well as communication and transfer to ensure personnel understanding. Dissemination of objectives from organizational level, to faculty level, to department level, and to personnel level is implemented. The researcher, therefore, suggests that public universities emphasize determining a clear vision and goals, raise personnel participation for implementation, and build mechanisms and channels of communication to ensure the same focus among all personnel of every unit.

From the findings, it is revealed that the current management quality assessment systems of all public universities employ the same key performance indicator determination guidelines, based on the management theory, and the same key performance indicator assessment details; even though those universities have different strategic contexts, visions, and missions. Under these circumstances, although each university has a different focus or 
strategic context, they have to be assessed by the same criteria and indicators, resulting in a failure of key performance indicators that are unable to include the main aspects and a failure to reflect management qualities that will support institutes to achieve their vision and goals. Therefore, the researcher suggests that assessment indicators of government organizations should be divided into 2 parts, including part 1: indicators that are developed based on management theory conforming to characteristics, missions, and context of public universities which are able to respond to educational policies of the country. These common key performance indicators will be similarly applied in each public university. In addition they should be selected minimally so that they will not be a huge responsibility for universities. Part 2: indicators that are developed based on links between the vision and goals of each university. These specific key performance indicators will be different for each university, according to strategic contexts and focus. It is recommended to allow universities themselves to determine their own key performance indicators to employ together with indicators from part 1 , which will be implemented as assessment indicators for each year.

\section{ACKNOWLEDGEMENT}

This research result is the part of "Development of Key Performance Indicator for Government Universities" thesis.

\section{AUTHOR INFORMATION}

Kritsana Sukboonyasatit, Ph.D. candidate, Development Science Course, Faculty of Humanities and Social Sciences Khonkaen University, Thailand who graduated master Degree of Business Administration, Chulalongkorn University Thailand, and Bachelor Degree of Accounting, Chiangmai University Thailand. E-mail: kritsana@bexcellence.co.th

Asst. Prof. Chaiwit Thanapaisarn, instructor, Faculty of Medicine Khonkaen University who graduated from Chulalongkorn University, Thailand. E-mail: chaiwit@kku.ac.th

Assoc. Prof. Lampang Manmart, Dean of Graduate School and instructor, Faculty of Humanities and Social Sciences, Khonkaen University, Thailand who graduated Ph.D. in communication from University of Canberra, Australia and M.Ed. Education Technology from Tsukuba University Japan. E-mail: lamman@kku.ac.th

\section{REFERENCES}

1. Ashworth, Allen. And R.C. Havey. (1994). Assessing Quality in Future and Higher Education. London: Jessica Kingsley Publishers.

2. Fong, Carolyn M. (1992). A Model for Peak Performance, Nursing Educator. July/August.

3. James N Johnstone, (1981). Indicators of Education Systems. UNESCO UK: The Anchor Press. Tiptree, Essex.

4. Joseph, Mathew and Beatriz Juseph. (1997). Service Quality in Education: A Student Perspective, Quality Assurance in Education.

5. Kaplan, R.S., \& Norton, D.P. (1992). The Balanced Scorecard - Measures that Drive Performance. Harvard Business Review, 70 - 79.

6. Kaplan, R.S., \& Norton, D.P. (1993). Putting the Balanced Scorecard to Work. Harvard Business Review, 71(5), 134-142.

7. Kaplan, R.S., \& Norton, D.P. (1996). Translating Strategy into Action: The Balanced Scorecard. Boston: Harvard Business School Press.

8. Kaplan, R.S., \& Norton, D.P. (1996). Using the Balanced Scorecard as a Strategic Management System. Harvard Business Review, 74(1), 75-85.

9. Malcolm Baldrige National Quality Award Program. (2003). Education Criteria for Performance Excellence. Gaithersburg, MD: Author.

10. Miller, R.I. (1979). The Assessment of College Performance. Jossey-Bass Publisher.

11. Oakes, J. (1976). Educational Indicators: A Guide for Policy Makes. New Brunswick: Center for Policy Research in Education, Rutges University.

12. Oliva, Mohammad S. and Elain M. Aspinwall. (1996). A Framework for the Dimension of Quality in Higher Education, Quality Assurance in Education. 
13. Rockart, Jack F. (1986). A Primer on Critical Success Factors published in The Rise of Managerial Computing: The Best of the Center for Information Systems Research. McGraw - Hill School Education Group.

14. Roger, M.E. (1988). The Nature and Characteristics of Professional Education for Nursing. Journal of Professional Nursing.

15. Tan, D.L. (1992). A Multivariate Approach to the Assessment of Quality. Research in Higher Education. April.

16. University of Wisconsin - Stout. (2001). University of Wisconsin - Stout 2001 Baldrige Application Summary. 